\title{
Tranexamic Acid, a Low-cost and Practical Hemostatic Agent Against Diffuse Microvascular Bleeding Due to Coagulopathy in Heart Surgery
}

\author{
(1) Kenan Abdurrahman Kara1, (1) Hakan Öntaş2
}

${ }^{1}$ Yeditepe University Hospital, Department of Cardiovascular Surgery, İstanbul, Turkey

${ }^{2}$ Balıkesir Atatürk City Hospital, Clinic of Cardiovascular Surgery, İstanbul, Turkey

\begin{abstract}
Objectives: Bleeding after open heart surgery is an important cause of morbidity and mortality. It may not always be related to surgical bleeding. Bleeding due to coagulopathy, called diffuse microvascular bleeding, is more commonly seen in the post-operative period. The objective of this study is to assess the effect of administering transamine, which we consider a low-cost and effective hemostatic agent, during open heart surgery on postoperative bleeding amount, blood product use, length of stay in intensive care, and duration of hospitalization.

Materials and Methods: A total of 24 patients were enrolled in the study at the Hisar Intercontinental Hospital between March 2017-December 2017. 12 patients were administered tranexamic acid $10 \% 500 \mathrm{mg}$ I.V. before starting sternal incision for open heart surgery. $10 \% 500 \mathrm{mg}$ I.V. tranexamic acid dose was repeated during separation from the heart-lung machine at the end of the operation.
\end{abstract}

The other 12 patients were followed-up as a control group. Patients were followed-up for drainage in the post-operative period. The patients were monitored for re-operation due to bleeding and significant side effects. Bleeding amounts and re-operation rates were compared.

Results: When the results from the two groups were evaluated, revision rates, amounts of used blood and blood products, total drainage amount were less, and stay in intensive care and discharge time were shorter in the group given tranexamic acid.

Conclusion: We think that tranexamic acid, which is used as a low-cost and effective pharmacological agent in heart surgery, will significantly reduce post-operative bleeding and the need for blood transfusion in patients undergoing heart surgery.

Keywords: Tranexamic acid, diffuse microvascular bleeding, coagulopathy after $\mathrm{CABG}$, re-operation

\footnotetext{
Address for Correspondence: Kenan Abdurrahman Kara, Yeditepe University Hospital, Clinic of Cardiovascular Surgery, İstanbul, Turkey Phone: +90 5300655225 e-mail: kenankaradoc@gmail.com ORCID ID: orcid.org/0000-0003-1295-7689

Received: 02.02.2019 Accepted: 21.02.2019

Cite this article as: Kara KA, Öntaş H. Tranexamic Acid, a Low-cost and Practical Hemostatic Agent Against Diffuse Microvascular Bleeding Due to Coagulopathy in Heart Surgery. EJCM 2019;7(1):16-21.

DOI: 10.32596/ejcm.galenos.2019.00003
} 


\section{Introduction}

Open heart surgeries bring out the need for blood and blood products ${ }^{(1)}$. Although heart surgeons avoid the use of blood and blood products, these are usually used in the post-operative period. Post-operative excessive blood loss can progress to anemia, hemodynamic changes, reoperation, and even mortality. Immunologic, metabolical and endocrinologycal disorders may develop as a result of post-operative excessive bleeding ${ }^{(2)}$. Moreover, excessive amount of blood transfusion during treatment may cause several complications. These include immunological reactions, anaphylaxis, sepsis and risk of viral infection transmission ${ }^{(2-4)}$. Blood transfusions carry a risk of complications such as fever, hemolytic reaction, allergic reaction, citrate toxicity, air embolism as well as transmitting blood-borne diseases (viral hepatitis, HIV, malaria, infectious mononucleosis and cytomegalovirus infections $)^{(5)}$. When we evaluate these complications, the importance of surgical bleeding control during open heart surgery becomes evident. However, no matter how carefully a surgeon controls the bleeding, sometimes bleeding cannot be prevented due to factors affecting coagulopathy. Coagulopathy causing such types of bleeding seen after open heart surgery is a frequent problem. It may be observed depending on several factors such as thrombocytopenia, platelet function disorder, loss of clotting factors, increased amount of free heparin ${ }^{(6-8)}$. In the studies conducted, 5-25\% life-threatening bleeding were seen in patients undergoing open heart surgery with cardiopulmonary bypass $(\mathrm{CPB})^{(9,10)}$, and $2-7 \%$ of patients required re-operation due to bleeding ${ }^{(3,11,12)}$. Re-operation in patients causes outcomes such as prolonged mechanical ventilation support, increased inotropic support, increased stay in intensive care, hypothermia caused by connecting to the heart-lung machine again, and coagulopathy. This considerably increases morbidity, mortality and hospital costs. Bleeding due to coagulopathy was detected in $50-80 \%$ of patients undergoing re-operation, rather than surgical bleeding ${ }^{(13)}$. During the re-operation, bleeding control performed by the surgeon generally cannot find an active bleeding focus and usually cauterizes the microbleeding focus leaking from the tissues. This suggests that the bleeding is related to an acute acquired hemostatic disorder. This clinical picture, called diffuse microvascular bleeding, is a coagulation disorder depending on many factors. Contributing factors to this picture are consumption of coagulation factors, platelet function disorder, rebound effect of heparin, excessive fibrinolysis, low platelet count, excessive heparin and protamine, complement activation and disseminated intravascular coagulation $^{(10-12)}$. The most frequent factors among these are excessive fibrinolysis (25-45\%) and platelet function disorder ${ }^{(2,3,14,15,19)}$. Various pharmacological agents have been used in recent years to reduce excessive bleeding during open heart surgery. Tranexamic acid, aprotinin, desmopressin and prostacyclins are among these pharmacological agents. Tranexamic acid is a synthetic hemostatic agent with antifibrinolytic activity. It inhibits the activity of plasminogen activators and plasmine ${ }^{(16-18,20)}$. In this study, we compared the bleeding amounts of two groups of patients in the post-operative period after open heart surgery, with and without intravenous administration of tranexamic acid.

\section{Materials and Methods}

The objective was to compare the effect of tranexamic acid on post-operative bleeding.

Twenty four patients underwent an isolated coronary artery bypass graft operation using CPB by a single surgeon between March 2017-December 2017 at the Hisar Intercontinental Hospital. In 12 patients (10 males, 2 females; mean age: 57.16) open heart surgery was started with routine heparinization. Neutralization was performed with protamine to weane the patient from the heart-lung machine. Twelve patients ( 8 males, 4 females; mean age: $56.25)$ were administered $10 \% 500 \mathrm{mg}$ I.V. before starting sternal incision for open heart surgery. $10 \% 500 \mathrm{mg} \mathrm{I.V.}$ tranexamic acid dose was repeated during separation from the heart-lung machine at the end of the operation. Patients were followed-up for drainage in the post-operative 
period. Bleeding amounts and re-operation rates were compared. The other 12 patients were followed-up as a control group, and transaminic acid was not administered. Extubation hours, drainage amounts, re-operation due to bleeding, withdrawal time of chest tubes, length of stay in intensive care and discharge time were reviewed.

Surgery was performed through a median sternotomy with cardiopulmonary bypass established through right atrial and ascending aortic cannulation. Intermittent cold cardioplegia was used in the initial 24 patients and blood cardioplegia thereafter. An intravenous second-generation cephalosporin antibiotic was administered intraoperatively and for 48 hours postoperatively for prophylaxis against infection.

Patients who were diabetic or had renal failure or experienced any cerebrovascular events were excluded from the study.

The most important limitation of this study was the small number of patients.

The authors declare that they are responsible for the article's scientific content including study design, data collection, analysis and interpretation, writing, some of the main line, or all of the preparation and scientific review of the contents and approval of the final version of the article. All procedures performed in this study were in accordance with the ethical standards of the institutional and/or national research committee and with the 1964 Helsinki Declaration and its later amendments or comparable ethical standards. No animal or human studies were carried out by the authors for this article.

The approval was obtained by the Yeditepe University Ethics Committee for this study (number: 13.02.2019/966). Written informed consent was obtained from the patients.

\section{Results}

In all patients enrolled, pre-operation hemoglobin, hematocrit, platelet count, prothrombine time, active partial thromboplastine time were within normal limits. There was no difference between the cases included in the study. All patients were discharged without any problems following operation.

When the results from the two groups were evaluated, revision rates, amounts of used blood and blood products, total drainage amount were less, and stay in intensive care and discharge time were shorter in the group given tranexamic acid (Table 1, Table 2, Table 3).

In the patient group receiving tranexamic acid systemically, the mean total amount of drainage was

Table 1. Operative and post-operative data of patients tranexamic acid group

\begin{tabular}{|c|c|c|c|c|c|}
\hline Procedure & ICU (day) & Hospital (day) & Drainage $(\mathrm{mL})$ & Age/gender & Used blood products \\
\hline $1-\operatorname{cabg} \times 3$ & 2 & 7 & 800 & $74 / M$ & $2 \mathrm{ES}$ \\
\hline $2-\operatorname{cabg} \times 3+C E$ & 3 & 6 & 900 & 63/M & $3 \mathrm{ES}$ \\
\hline 4-cabgx4 & 2 & 5 & 800 & $64 / M$ & $2 \mathrm{ES}$ \\
\hline 5 -cabgx3 & 2 & 5 & 750 & $42 / \mathrm{M}$ & $2 \mathrm{ES}$ \\
\hline 8-cabgx3 & 3 & 7 & 900 & $55 / F$ & $1 \mathrm{ES}$ \\
\hline $9-\operatorname{cabg} x 3$ & 2 & 8 & 700 & $66 / F$ & $1 \mathrm{ES}$ \\
\hline $10-\operatorname{cabg} \times 3$ & 2 & 7 & 700 & $62 / \mathrm{M}$ & $1 \mathrm{ES}$ \\
\hline $11-c a b g \times 3$ & 3 & 7 & 800 & 70/M & $2 \mathrm{ES}$ \\
\hline
\end{tabular}


$775 \mathrm{~mL}$, and the mean amount of used blood and blood products was 1.83 units of erythrocyte while in the patients not given tranexamic acid systemically, the mean amount of drainage was $850 \mathrm{~mL}$ and the mean amount of used blood and blood products was 2.5 units of erythrocyte and a total of 2 units of platelets following the operation. One patient in the group not administered tranexamic acid was retaken into the operation room from intensive care unit for bleeding revision 4 hours after the end of the operation. No surgical foci were detected during the bleeding control performed on the patient. The bleeding foci in the form of leakage were cauterized. The patient was then submitted back to intensive care.

Table 2. Measured pre-operative and per-operative variables of 24 patients

\begin{tabular}{l|l|}
\hline Hypertension & 18 \\
\hline Peripheral vascular disease & 2 \\
\hline IABP insertion & 1 \\
\hline Emergent surgery & 1 \\
\hline Hyperlipidemia & 18 \\
\hline History of smokin & 20 \\
\hline Respiratory failure & 0 \\
\hline Reexploration for bleeding & 1 \\
\hline COPD & 14 \\
\hline IABP: Intra-aortic balloon pump, COPD: Chronic obstructive pulmonary \\
disease
\end{tabular}

Table 3. Operative and post-operative data of patients without tranexamic acid

\begin{tabular}{|c|c|c|c|c|c|}
\hline Procedure & ICU (day) & Hospital (day) & Drainage (mL) & Age/gender & Used blood products \\
\hline 1-cabgx4 & 2 & 8 & 900 & $48 / \mathrm{M}$ & $3 \mathrm{ES}, 1$ thromb \\
\hline $2-\operatorname{cabg} x 3$ & 2 & 6 & 850 & $56 / \mathrm{M}$ & $3 \mathrm{ES}$ \\
\hline $4-\operatorname{cabg} \times 3$ & 2 & 8 & 800 & $58 / \mathrm{M}$ & $2 \mathrm{ES}$ \\
\hline 5 -cabgx2 & 3 & 8 & 850 & $49 / \mathrm{M}$ & $2 \mathrm{ES}$ \\
\hline $8-\operatorname{cabg} x 3$ & 2 & 7 & 800 & $57 / \mathrm{M}$ & $2 \mathrm{ES}$ \\
\hline $9-\operatorname{cabg} \times 3$ & 3 & 7 & 900 & $60 / F$ & $3 \mathrm{ES}$ \\
\hline $10-\operatorname{cabg} x 2$ & 3 & 7 & 800 & $62 / F$ & $2 \mathrm{ES}$ \\
\hline $11-\operatorname{cabg} x 2$ & 2 & 7 & 900 & $68 / \mathrm{M}$ & $2 \mathrm{ES}$ \\
\hline
\end{tabular}

Surgical bleeding seen in some of the patients after open heart surgery can be stopped with an reintervention. However, sometimes a disseminated and in the hemostatic system. These kinds of bleeding may be seen due to thrombocytopenia, reduction of clotting factors, increase of fibrinolysis, excessive heparinization, insufficient heparin neutralization, and the rebound effect of heparin. Giving excessive amounts of protamine as well as insufficient heparin neutralization may have side effects on the cardiovascular system. In the study conducted, tranexamic acid was administered to heart surgery patients at risk of high transfusion ${ }^{(16)}$. It was observed that the blood product use and drainage amounts in patients who were administered tranexamic acid were reduced ${ }^{(17)}$.

Tranexamic acid is known to have topical applications in addition to its systemic use. Its administration into the pericardial cavity in patients undergoing elective coronary artery bypass surgery was reported to significantly reduce the post-operative blood loss and the need for transfusion and to block side effects ${ }^{(10)}$. Fawyz et al. reported that topical application of tranexamic acid for bleeding control following open heart surgery reduced post-operative blood

\section{Discussion} heavy bleeding may be observed, suggesting a disorder 
loss and that it did not pose any risks for the patient ${ }^{(21-23)}$. Another study by Abdul-Azm et al. demonstrated that the use of topical tranexamic acid reduced post-operative mediastinal bleeding and reexploration ${ }^{(24)}$. It was reported that administration of tranexamic acid at various doses during the operation reduced blood loss and the need for transfusion but it did not have any long-term benefits. It was also shown that administering a low dose of tranexamic acid after coronary artery bypass surgery significantly reduced the bleeding amount and the need for blood transfusion ${ }^{(25-27)}$.

All patients who are followed up after angio stent procedure into heart surgery or with a congenital adrenal hyperplasia diagnosis already use routine acetylsalicylic acid or clopidogrel and, in some cases, other drugs such as tirofiban or ticagrelor, which have a high risk of bleeding. Development of bleeding diathesis is also quite high in these patients with a history of using these medicines. When all these strong medicines affecting the coagulation cascade are evaluated, a simple administration of tranexamic acid alone is of course not enough for bleeding control. However it has a non-negligible beneficial effect in terms of economy and effectiveness, as shown in this study ${ }^{(28-30)}$.

Based on the study we performed, we think that systemic use of tranexamic acid relatively causes a decrease in post-operative bleeding amount and the amounts of used blood transfusions and blood products compared to the control group. However, the most important limitation of this study was the small number of patients studied.

We think that tranexamic acid, which we administered before incision in the per op period and after the operation, is a quite simple, practical and economic hemostatic agent. Tranexamic acid significantly reduces postoperative bleeding and blood transfusion requirement in heart surgery patients. In conclusion, systemic use of tranexamic acid in open heart surgery caused a decrease in post-operative bleeding amount without producing any side effects.

\section{Ethics}

Ethics Committee Approval: The approval was obtained by the Yeditepe University Ethics Committee (number: 13.02.2019/966).

Informed Consent: Written informed consent was obtained from the patients.

Peer-review: Externally peer-reviewed.

\section{Authorship Contributions}

Surgical and Medical Practices: K.A.K., Concept: K.A.K., Design: K.A.K., Data Collection or Processing: K.A.K., H.Ö., Analysis or Interpretation: K.A.K., H.Ö., Literature Search: K.A.K., H.Ö., Writing: K.A.K.

Conflict of Interest: No conflict of interest was declared by the authors.

Financial Disclosure: The authors declared that this study received no financial support.

\section{References}

1. Yeh T Jr, Shelton L, Yeh TJ. Blood loss and bank blood requirement in coronary bypass surgery. Ann Thorac Surg 1978;26:11-6.

2. Huang H, Ding W, Su Z, Zhang W. Mechanism of the preserving effect of aprotinin on platelet function and its use in cardiac surgery. J Thorac Cardiovasc Surg 1993;106:11-8.

3. Casati V, Guzzon D, Oppizzi M, et al. Tranexamic acid compared with high-dose aprotinin in primary elective heart operations: effects on perioperative bleeding and allogeneic transfusions. J Thorac Cardiovasc Surg 2000;120:520-7.

4. Mongan PD, Brown RS, Thwaites BK. Tranexamic acid and aprotinin reduce postoperative bleeding and transfusions during primary coronary revascularization. Anesth Analg 1998;87:258-65.

5. Zuck TF. Transfusion-transmitted AIDS reassessed. $\mathrm{N}$ Engl J Med 1988;318:511-2.

6. Kucuk O, Kwaan HC, Frederickson J, Wade L, Green D. Increased fibrinolytic activity in patients undergoing cardiopulmonary bypass operation. Am J Hematol 1986;23:223-9.

7. Harker LA, Malpass TW, Branson HE, Hessel EA, Slichter SJ. Mechanism of abnormal bleeding in patients undergoing cardiopulmonary bypass: acquired transient platelet dysfunction associated with selective alphagranule release. Blood 1980;56:824-34.

8. Despotis GJ, Santoro SA, Spitznagel E, Kater KM, Cox JL, Barnes P, Lappas DG. Prospective evaluation and clinical utility of on-site monitoring of coagulation in patients undergoing cardiac operation. J Thorac Cardiovasc Surg 1994;107:271-9.

9. Lemmer JH, Stanford W, Bonney SL, et al. Aprotinin for coronary bypass operations: efficacy, safety, and influence on early saphenous vein graft 
patency. A multicenter, randomized, double-blind, placebo-controlled study. J Thorac Cardiovasc Surg 1994;107:543-51.

10. Tatar H, Çiçek S, Demirkiliç U, et al. Topical use of aprotinin in open heart operations. Ann Thorac Surg 1993;55:659-61.

11. De Bonis M, Cavaliere F, Alessandrini F, et al. Topical use of tranexamic acid in coronary artery bypass operations: a double-blind, prospective, randomized, placebo-controlled study. J Thorac Cardiovasc Surg 2000;119:575-80

12. Rocha E, Hidalgo F, Llorens R, Melero JM, Arroyo JL, Páramo JA. Randomized study of aprotinin and DDAVP to reduce postoperative bleeding after cardiopulmonary bypass surgery. Circulation 1994;90:9217.

13. Daily PO, Lamphere JA, Dembitsky WP, Adamson RM, Dans NF. Effect of prophylactic epsilon-aminocaproic acid on blood loss and transfusion requirements in patients undergoing first-time coronary artery bypass grafting. A randomized, prospective, double-blind study. J Thorac Cardiovasc Surg 1994;108:99-106.

14. Jamieson WR, Dryden PJ, O'Connor JP, Sadeghi H, Ansley DM, Merrick PM. Beneficial effect of both tranexamic acid and aprotinin on blood loss reduction in reoperative valve replacement surgery. Circulation 1997;96(Suppl 9):96-100.

15. Katoh J, Tsuchiya K, Sato W, Nakajima M, Iida Y. Additional postbypass administration of tranexamic acid reduces blood loss after cardiac operations. J Thorac Cardiovasc Surg 1997;113:802-4.

16. Wong BI, McLean RF, Fremes SE, et al. Aprotinin and tranexamic acid for high transfusion risk cardiac surgery. Ann Thorac Surg 2000;69:808-16.

17. Bidstrup BP, Harrison J, Royston D, Taylor KM, Treasure T. Aprotinin therapy in cardiac operations: a report on use in 41 cardiac centers in the United Kingdom. Ann Thorac Surg 1993;55:971-6.

18. Dodsworth H, Dudley HA. Increased efficiency of transfusion practice in routine surgery using pre-operative antibody screening and selective ordering with an abbreviated crossmatch. Br J Surg 1985;72:102-4.

19. Ferraris VA, Brown JR, Despotis GJ, et al. 2011 update to the Society of Thoracic Surgeons and the Society of Cardiovascular Anesthesiologists blood conservation clinical practice guidelines. Ann Thorac Surg 2011;91:944-82.

20. Myles PS, Smith JA, Forbes A, et al. Tranexamic Acid in Patients Undergoing Coronary-Artery Surgery. N Engl J Med 2017;376:136-48.

21. Casati V, Sandrelli L, Speziali G, Calori G, Grasso MA, Spagnolo S. Hemostatic effects of tranexamic acid in elective thoracic aortic surgery: a prospective, randomized, double-blind, placebo-controlled study. J Thorac Cardiovasc Surg 2002;123:1084-91.

22. Ker K, Edwards P, Perel P, Shakur H, Roberts I. Effect of tranexamic acid on surgical bleeding: systematic review and cumulative meta-analysis. BMJ 2012;344:e3054.

23. Fawzy H, Elmistekawy E, Bonneau D, Latter D, Errett L. Can local application of Tranexamic acid reduce post-coronary bypass surgery blood loss? A randomized controlled trial. J Cardiothoracic Surg 2009;4:25.

24. Abul-Azm A, Abdullah KM. Effect of topical tranexamic acid in open heart surgery. Eur J Anaesthesiol 2006;23:380-4.

25. Sharma V, Fan J, Jerath A, et al. Pharmacokinetics of tranexamic acid in patients undergoing cardiac surgery with use of cardiopulmonary bypass. Anaesthesia 2012;67:1242-50

26. Casati V, Bellotti F, Gerli C, et al. Tranexamic acid administration after cardiac surgery: a prospective, randomized, double-blind, placebocontrolled study. Anesthesiology 2001;94:8-14.

27. Zabeeda D, Medalion B, Sverdlov M, et al. Tranexamic acid reduces bleeding and the need for blood transfusion in primary myocardial revascularization. Ann Thorac Surg 2002;74:733-8.

28. Wąsowicz M, Jerath A, Bojko B, Sharma V, Pawliszyn J, McCluskey S. Use of a novel technique, solid phase microextraction, to measure tranexamic acid in patients undergoing cardiac surgery. Can J Anaesth 2012;59:14-20.

29. Manji RA, Grocott HP, Leake J, et al. Seizures following cardiac surgery: the impact of tranexamic acid and other risk factors. Can J Anaesth 2012;59:6-13.

30. Kalavrouziotis D, Voisine P, Mohammadi S, Dionne S, Dagenais F. Highdose tranexamic acid is an independent predictor of early seizure after cardiopulmonary bypass. Ann Thorac Surg 2012;93:148-54. 